\title{
Prevalence of Infectious Skin Diseases in Psychiatric Patients
} H.H.Sabry ${ }^{1}$, R.M.Salem ${ }^{1}$, H.E.Bayomy ${ }^{2}$ and E.E.Soliman ${ }^{1}$

${ }^{1}$ Dermatology, Venereology and Andrology Dept., Faculty of Medicine, Benha Univ., Benha ,Egypt

${ }^{2}$ Community Medicine Dept, Faculty of Medicine, Benha Univ., Benha, Egypt

E-Mail: enasaisa1988@yahoo.com

\begin{abstract}
Psychodermatology is an underappreciated field that studies psychocutaneous disorders, which are conditions that have both dermatologic and psychiatric characteristics. Underlying psychiatric comorbidity is estimated to occur in up to one-third of dermatologic patients, and psychiatric illness may either be the cause or the consequence of dermatologic disease. The present work aims to identify the type and frequency rate of infectious skin diseases among patients with psychiatric diseases. 500 patients with primary psychiatric disorders and 199 healthy controls from the Benha City, Qalyubia Governorate, Egypt were included in the study and were diagnosed according to The Diagnostic and Statistical Manual of Mental Disorders (DMS V) Criteria. A specially designed questionnaire including socio-demographic data , dermatological and general medical examination was applied. The data were statistically analyzed. There was a significant statistical increase in the prevalence of infectious skin diseases in psychiatric patients compared with nonpsychiatric patients. Health education of psychiatric patients and/or of their caregiver and periodic monthly inspection of psychiatric patients are highly indicated for the prevention and control of infectious skin diseases in these patients.
\end{abstract}

Key words: Psychodermatology, Infectious skin diseases, Psychiatric comorbidity.

\section{Introduction}

A psycho-dermatologic disorder is a condition that involves an interaction between the mind and the skin. Psycho-dermatologic disorders fall into three categories; psycho-physiologic disorders, primary psychiatric disorders and secondary psychiatric disorders [1]. Psychophysiologic disorders, e.g. psoriasis and eczema, are associated with skin problems that are not directly connected to the mind but that react to emotional states such as stress. Primary psychiatric disorders involve psychiatric conditions that result in self-induced cutaneous manifestations, such as trichotillomania and delusions of parasitosis. Secondary psychiatric disorders are associated with disfiguring skin disorders. The disfigurement results in psychologic problems, such as decreased self-esteem, depression or social phobia [2]. Psychiatric patients often have a defensive need to deny their psychopathology and seek dermatological care for their prominent cutaneous symptoms. It has been estimated that the effective management of at least one third of the patients in dermatological departments depends upon the recognition of the emotional factor [3]. Understanding the psychosocial and occupational context of skin diseases is critical to the optimal management of psycho-dermatologic disorders. The management of psycho-dermatologic disorders requires evaluation of the skin manifestations and the social, familial and occupational issues underlying the problem. Once the disorder has been diagnosed, management requires a dual approach, addressing both dermatologic and psychologic aspects [4]. Even with selfinduced skin problems, supportive dermatologic care is needed to avoid secondary complications, such as infection, and to ensure that the patient feels supported [5].

However, there is very little published data on the frequency of dermatoses in patients with psychiatric diseases. The rational of this study was to investigate the occurrence of skin diseases in psychiatric patients in order to develop effective management for these diseases [6]. The aim of the present study is to identify the type and frequency rate and risk factors of infectious skin diseases among patients with psychiatric diseases and to outline preventive and control strategies forinfectious skin diseases in these patients.

\section{Subjects and Methods}

This is a comparative cross-sectional study, which was conducted on 500 patients with primary psychiatric disorders and 199 healthy controls from Benha City, Qalyubia Governorate, Egypt. Qalyubia Governorate is one of the governorates of Egypt. Located in the Lower Egypt, in the North of Cairo in the Nile Delta region. Its capital is Benha. The work was carried out during the period from January to June 2018. An approval from the Research Ethics Committee in Benha faculty of medicine was obtained to conduct this study. Psychiatric patients attending Benha University hospital Psychiatric Department outpatient clinic who fulfilled the inclusion criteria during the period of the study and accepted to take part in this project were recruited in the study. Control subjects were selected from patients'relatives and from the different clinics. Patients included in the study were those with primary psychiatric diseases as diagnosed by a psychiatric consultation based on The Diagnostic and Statistical Manual of Mental Disorders (DMS V) Criteria of both genders and age $\geq 18$ years. Patients excluded from this study were those with chronic diseases including diabetes mellitus, Cardiovascular diseases, liver diseases, renal diseases and endocrinal disorders. The least number of patients (323 participants) to be included in the study is determined according to the following equation: 
Sample size $=\frac{\mathrm{Z}_{1-\propto / 2}{ }^{2} P(1-P)}{d^{2}}$

Where: $\mathrm{Z} 1-\alpha / 2=$ is the standard normal variate at $5 \%$ type 1 error $(\mathrm{P}<0.05)$; it is 1.96 .

$\mathrm{P}=$ the expected proportion based on previous studies $(\approx 70 \%) . \mathrm{D}=$ the absolute error $(0.05)$

All the participants in the study were subjected to full history taking, psychiatric consultation, dermatological examination and general medical examination. The collected data were described as mean \pm Standard Deviation (SD) and range for quantitative data and frequencies and percentages for qualitative data. Comparisons between the different study groups were carried out using the test of proportion (Z-test) to compare two proportions and the Chi-square test and the Fisher Exact Test to compare more than two proportions as appropriate. The independent t-test and one way Analysis Of Variance (ANOVA; F) were used to detect mean differences between two and more than two groups respectively.

Statistical significance was accepted at $P$ value $<0.05$ (S). A P value $<0.001$ was considered highly significant (HS) while a $\mathrm{P}$ value $>0.05$ was considered non-significant. All statistical analyses were carried out in STATA/SE version 11.2 for Windows (STATA Corporation, College Station, Texas).

\section{Results and discussion}

There was no significant statistical difference regarding age and sex among the studied groups Table (1). The prevalence of infectious skin diseases among the psychiatric patients was significantly higher than the control group Table (2). The most common cutaneous infections in the two studied groups were fungal infections with no significant difference in the prevalence. The prevalence of parasitic infestations in psychiatric patients was significantly higher than that in the control subjects $(\mathrm{p}<0.001)$ Table (3).

Table (1) Demographic data of the studied groups

\begin{tabular}{|c|c|c|c|c|c|c|c|}
\hline \multicolumn{2}{|c|}{ Variable } & \multicolumn{2}{|c|}{$\begin{array}{l}\text { Psychiatric patients } \\
\text { (no.=500) }\end{array}$} & \multicolumn{2}{|l|}{$\begin{array}{l}\text { Control } \\
(\text { no.=199) }\end{array}$} & \multirow{2}{*}{$\begin{array}{l}\text { Chi- } \\
\text { square } \\
\text { test }\end{array}$} & \multirow[t]{2}{*}{$\mathbf{P}$} \\
\hline & & No. & $\%$ & No. & $\%$ & & \\
\hline \multirow[t]{2}{*}{ Sex } & Male & 281 & 56.20 & 112 & 56.28 & 0.0004 & 0.98 \\
\hline & Female & 219 & 43.80 & 87 & 43.72 & & \\
\hline \multicolumn{2}{|c|}{ Age (years) } & $\begin{array}{l}\text { Mean } \pm \text { SD } \\
36.19 \pm 12.70\end{array}$ & $\begin{array}{l}\text { Range } \\
18-64\end{array}$ & $\begin{array}{l}\text { Mean } \pm \text { SD } \\
35.54 \pm 11.39\end{array}$ & $\begin{array}{l}\text { Range } \\
20-62\end{array}$ & $\begin{array}{l}\text { t-test } \\
0.66\end{array}$ & $\begin{array}{l}\mathrm{P} \\
0.51\end{array}$ \\
\hline
\end{tabular}

Table (2) Prevalence of infectious skin diseases among the studied groups

\begin{tabular}{|c|c|c|c|c|c|c|}
\hline \multirow{3}{*}{ Infectious skin diseases } & \multicolumn{2}{|c|}{$\begin{array}{l}\text { Psychiatric patients } \\
\text { (no.=500) }\end{array}$} & \multicolumn{2}{|c|}{$\begin{array}{l}\text { Control } \\
(\text { no.=199) }\end{array}$} & \multirow[t]{2}{*}{$\begin{array}{l}\text { Chi- } \\
\text { square test }\end{array}$} & \multirow[t]{2}{*}{$\mathbf{P}$} \\
\hline & No. & $\%$ & No. & $\%$ & & \\
\hline & 425 & 85.0 & 156 & 78.39 & 4.43 & $\begin{array}{l}0.03 \\
(\mathrm{~S})\end{array}$ \\
\hline
\end{tabular}

P: Probability

S: Significant difference $(\mathrm{P}<0.05)$

Table (3) Comparison between the studied groups regarding types of skin infections.

\begin{tabular}{|c|c|c|c|c|c|c|c|}
\hline & \multirow[t]{2}{*}{ Variable } & \multicolumn{2}{|c|}{$\begin{array}{l}\text { Psychiatric } \\
\text { patients } \\
(\text { no.=500) }\end{array}$} & \multicolumn{2}{|c|}{$\begin{array}{l}\text { Control } \\
(\text { no.=199) }\end{array}$} & \multirow[t]{2}{*}{$\begin{array}{l}z- \\
\text { test }\end{array}$} & \multirow[t]{2}{*}{$\mathbf{P}$} \\
\hline & & No. & $\%$ & No. & $\%$ & & \\
\hline \multirow{4}{*}{$\begin{array}{l}\text { Types of } \\
\text { diseases }\end{array}$} & Bacterial infections & 118 & 23.6 & 48 & 24.12 & 0.15 & 0.88 \\
\hline & Viral infections & 69 & 13.8 & 26 & 13.07 & 0.25 & 0.80 \\
\hline & Parasitic infections & 62 & 12.4 & 4 & 2.01 & 4.24 & $\begin{array}{l}<0.001 \\
\text { (HS) }\end{array}$ \\
\hline & Fungal infections & 176 & 35.2 & 78 & 39.2 & 0.99 & 0.32 \\
\hline
\end{tabular}

P: Probability

Z-test: two groups test of proportion

HS: Highly Significant difference $(\mathrm{P}<0.001)$ 
Psychodermatology is a newer and emerging subspecialty of dermatology, which bridges psychiatry, psychology, pediatrics and dermatology[7]. Psychodermatology begins by considering the profound effects on the psyche and on the physical and physiological development of the individual caused simply by touching the skin. This is a magical mechanism performed by the skin, which should be in the consciousness of every dermatologist [8]. The skin is intensely affected by everything that goes on in the mind and retrogradely, triggers thoughts and emotions. There is a permanent mind nervous system - skin connection and a reciprocal relation between these three areas. Skin sends messages to the nervous system and the mind and this influences the skin. From this interaction, the field of Psychodermatology was developed [9]. In the present study, a clear positive relation was detected between psychiatric disorders and the presence of infectious skin diseases. This study showed that the prevalence of infectious skin diseases was significantly higher in psychiatric patients than that in the control subjects Table(2). This is attributed to lack of patient awareness and negligence of self hygiene and personal care. This is in accordance with previous studies[1],[10] in which there were a higher percentage of infectious skin diseases in psychiatric patients than that in the non-psychiatric controls. Another study(11) reported that psychiatric disorders and chronic stress in adults are consistently associated with decreased natural killer (NK) cell cytotoxicity and decreased lymphocyte proliferation leading to increased susceptibility to infectious skin diseases. This is in contrast to aprevious study[13] that found a higher prevalence of infectious skin diseases in nonpsychiatric controls than that in the psychiatric patients. Among infective dermatoses in the current study fungal infections were the commonest in both control and patients groups followed by bacterial, viral and lastly parasitic infestations. However, parasitic infestations only were significantly higher in psychiatric patients than that in the control subjects. This is in accordance with astudy (1) that found that parasitic infestations in psychiatric patients were significantly higher than that in the non-psychiatric controls. This is because both studies were conducted in Egypt which is considered as one of the developing countries where infections spread due to poor hygiene and low socioeconomic status and may be mainly attributable to a lack of appropriate health awareness and care, which has created a tendency within the population to adapt without complaining or seeking medical help. Another study [10] found that dermatophyte infections were significantly higher in psychiatric patients than that in the control subjects. They explained their findings by the overall rising incidence of fungal infections in population due to increasing resistance against antifungals and steroid misuse. The treatment approaches for psychodermatological disorders starts with a good doctor-patient relationship to develop empathy and increase patient adherence and satisfaction. A multidisciplinary team, including dermatologists, psychiatrists, psychologists and social services are also very important for asuccessful treatment [9].

Thus, dealing with the patient and the treatment to be employed will require a more comprehensive performance of the dermatologist which enable him to recognize mental and emotional states that accompany dermatoses and to give psychological support to the patient, starting with a highly effective physicianpatient relationship, stress management resources and even psychopharmacological and psychological therapies. In addition dermatologists need the integration with professionals in Psychology and Psychiatry to attend specific cases of these specialties [13]. Therefore, Psychodermatology is a field of integrated action of three specialties without which it will not be possible to give the appropriate care to the patient. It should be added that the participation of Psychology and Psychiatry will not always result in the elimination of the disease. In many cases the objective is not a complete cure but the attention to the mental and emotional states that are part of the clinical picture in order to at least give the patient resources to deal with the problem in a balanced and autonomous manner [14]. The psychodermatology multidisciplinary team (pMDT) has been identified as a successful and costeffective way to manage this group of patients. The pMDT includes a dermatologist, a psychiatrist and/or a psychologist, with additional support from dermatology specialist nurses, child and adolescent mental health specialists, paediatricians, geriatricians and older age psychiatrists, social workers, trichologists, primary care physicians, child and/or vulnerable adult protection teams, patient advocacy and support groups [13]. Patients who present to a psychodermatology clinic usually believe they have a primary skin lesion. A clinician must approach the patient in the same way as they approach all patients they see in a dermatology clinic. Active listening is crucial with an in-depth comprehensive medical history (including substance misuse) and a full examination of the skin. By performing a detailed skin examination patients are reassured that their condition is being considered seriously, which will enhance engagement of the patient with the clinician. During the discussion with the patient, the concept of skin disease having an impact on a person's psychosocial well-being can be introduced. This then gently establishes the acceptability of carrying out a more detailed psychiatric assessment and structured management plan [6]. 


\section{Conclusion}

From the current study it was concluded that the high prevalence of skin diseases in psychiatric patients and addicts raises the need to develop psychodermatology clinics for better management of these challenging and difficult cases.

\section{References}

[1] N.H. Moftah, A.M. Kamel, H.M. Attia, M.Z. El-Baz, H.M. Abd El-Moty, Skin diseases in patients with primary psychiatric conditions. a hospital based study. J Epidemiol Glob Health,vol. 3(3),pp.131-138,2013.

[2] H.D. Korabel, A. Jaworek. Psychological and psychiatrical aspects of dermatology, Przegl Lek, vol. 65, pp. 244-248,2008.

[3] T. Kawahara, L. Henry, L. Mostaghimi, Needs assessment survey of psychocutaneous medicine. Int J Dermatol, vol. 48, pp.1066-1070, 2009.

[4] J.M. Bikowski, Dermatological manifestation of psychiatric disease. Practical dermatology. J Psychiatry, vol. 54, pp. 331, 2009.

[5] E.J. Mookhoek, P.C. Van De Kerkhof , J.E. Hovens , J.R. Brouwers, A.J. Loonen, Skin disorders in chronic psychiatric illness. JEur Acad Dermatol Venereol, vol. 24, pp. 1151-1156, 2010.

[6] M. Jafferany. Psychodermatology, Aguide to under standing common psychocutaneous disorders.J Clin, vol. 9, pp 203-213, 2007.

[7] C. Marshall, R. Taylor, A. Bewley, Psychodermatology in Clinical Practice. Main
Principles.Acta Derm Venereol, Vol. (96)217, pp 30-34, 2016.

[8] C. Rodríguez-Cerdeira, J.T. Pera-Grasa, A. Molares, R. Isa-Isa, R. Arenas-Guzmán, Psychodermatology: Past, Present and Future.The Open Dermatology Journal, vol. ( 5), pp 21-27, 2011.

[9] M. Jafferany, K. Franca, Psychodermatology: Basics Concepts.Acta Derm Venereol, vol 96(217), pp 35-37,2016.

[10] M. Kuruvila, P. Gahalaut, A. Zacharia, A study of skin disorders in patients with primary psychiatric conditions. Indian J Dermatol Venereol Leprol,vol. 70(5), pp.292-295,2004.

[11] S.C. Segerstrom, G.E. Miller, Psychological stress and the human immune system. a meta-analytic study of 30 years of inquiry.Psychol Bull, vol.130(4),pp.601-630, 2004.

[12] V. Gupta, A. Kapoor,S. Ganjoo, skin disorders in patients with primary psychiatric conditions in rural population in gurugram. Int. J. Adv. Re, vol. 5(4), pp. 1788-1791, 2017.

[13] S. Aguilar-Duran, A. Ahmed, R. Taylor,A. Bewley, How to set up a psychodermatology clinic.Clin Exp Dermatol, vol. 39(5), pp. 577-582, 2014.

[14] R.D. Azambuja, The need of dermatologists, psychiatrists and psychologists joint care in psychodermatology. An Bras Dermatol, vol. 92(1), pp. 63-71, 2017. 